\title{
Navigation-Assisted Balloon Eustachian Tuboplasty for Eustachian Tube Dilatory Dysfunction
}

\author{
Sung-Won Choi iD $\cdot$ Seok-Hwan Lee (iD $\cdot$ Se-Joon Oh (iD $\cdot$ Soo-Keun Kong (i) \\ Department of Otorhinolaryngology and Biomedical Research Institute, Pusan National University Hospital, \\ Pusan National University School of Medicine, Busan, Korea
}

Objectives. Balloon Eustachian tuboplasty (BET) is a novel treatment method for Eustachian tube dilatory dysfunction (ETD). However, surgeons cannot identify the insertion depth of the catheter during BET, resulting in potential risks such as internal carotid artery (ICA) injury. Therefore, we developed an image-guided navigation balloon catheter to identify the insertion depth of the catheter and to establish awareness of the proximity of the ICA. This study aimed to evaluate the technical feasibility of this image-guided navigation balloon catheter system in patients with ETD.

Methods. Twenty-nine patients (38 ears; nine bilateral; 21 right ears, and 17 left ears) diagnosed with ETD were assessed. All patients who showed no improvement despite medical therapy with topical steroids, anti-reflux medication, and the Valsalva maneuver for a minimum of 6 weeks received image-guided navigation-assisted BET. The 7-item Eustachian Tube Dysfunction Questionnaire (ETDQ-7) score and Valsalva maneuver were used to evaluate patients' symptoms preoperatively and at the postoperative follow-up.

Results. Image-guided navigation-assisted BET was safely performed in all patients. The mean total ETDQ-7 score was $25.4 \pm 7.1$ preoperatively, $17.5 \pm 6.2$ at 1 month, and $15.2 \pm 7.0$ at 6 months $(P<0.001)$. In total, a Valsalva maneuver was possible for 28 of 38 ears $(73.7 \%)$ at the time of the patient's final visit at 6 months post-procedure.

Conclusion. Image-guided navigation balloon catheters are a potentially valuable tool in patients with ETD. Their use is also technically feasible and safe when performing BET to treat ETD.

Keywords . Eustachian Tube; Dilatation; Dysfunction; Trauma; Navigation system

\section{INTRODUCTION}

Balloon dilatation of the Eustachian tube (balloon Eustachian tuboplasty [BET]) is a novel treatment method for Eustachian tube dilatory dysfunction (ETD) [1-3]. Since Ockermann et al. [4] introduced endoscopic BET in 2010, evidence of its shortterm and long-term benefits has accumulated [4-7]. However, the potential risks of BET include development of a circumferential stricture, fracture of the medial cartilaginous lamina, hem-

\footnotetext{
- Received August 12, 2019

Revised February 10, 2020

Accepted February 11, 2020

- Corresponding author: Soo-Keun Kong

Department of Otorhinolaryngology and Biomedical Research Institute, Pusan National University Hospital, Pusan National University School of Medicine, 179 Gudeok-ro, Seo-gu, Busan 49241, Korea

Tel: +82-51-240-7335, Fax: +82-51-246-8668

E-mail: entkong@gmail.com
}

orrhage into the pterygoid space, and excessive widening causing a patulous Eustachian tube (ET) [8].To date, it has not been possible for surgeons to identify the insertion depth of the catheter during BET. Excessively deep insertion of the guide wire could cause the wire to pass into the middle ear, injuring the ossicles or tympanic membrane [8]. The catheter may also become contorted in the ET during insertion and fail to dilate to the correct position. In addition, there is a risk that the catheter could injure the internal carotid artery (ICA) because of the close anatomical relationship between the bony ET and the ICA [9]. Carotid injury has been reported during BET procedures in a cadaveric study [10]. Additionally, previous studies have anecdotally reported catastrophic injuries and deaths during patulous ET injection procedures [11]. To avoid causing a devastating injury, it is clinically important to recognize the proximity of the ICA. Thus, we developed an image-guided navigation balloon catheter that could be used during BET for ETD to identify the

Copyright $\odot 2020$ by Korean Society of Otorhinolaryngology-Head and Neck Surgery.

This is an open-access article distributed under the terms of the Creative Commons Attribution Non-Commercial License (https://creativecommons.org/licenses/by-nc/4.0)

which permits unrestricted non-commercial use, distribution, and reproduction in any medium, provided the original work is properly cited. 
Table 1. The 7-item Eustachian Tube Dysfunction Questionnaire [12]

\begin{tabular}{|c|c|c|c|c|c|c|c|}
\hline \multirow{2}{*}{$\begin{array}{l}\text { Over the past } 1 \text { month, how much has each of the following been a problem for you? } \\
\text { 1. Pressure in the ears? }\end{array}$} & \multicolumn{2}{|c|}{ No problem } & \multicolumn{3}{|c|}{ Moderate problem } & \multicolumn{2}{|c|}{ Severe problem } \\
\hline & 1 & 2 & 3 & 4 & 5 & 6 & 7 \\
\hline 2. Pain in the ears? & 1 & 2 & 3 & 4 & 5 & 6 & 7 \\
\hline 3. A feeling that your ears are clogged or "under water"? & 1 & 2 & 3 & 4 & 5 & 6 & 7 \\
\hline 4. Ear symptoms when you have a cold or sinusitis? & 1 & 2 & 3 & 4 & 5 & 6 & 7 \\
\hline 5. Crackling or popping sounds in the ears? & 1 & 2 & 3 & 4 & 5 & 6 & 7 \\
\hline 6. Ringing in the ears? & 1 & 2 & 3 & 4 & 5 & 6 & 7 \\
\hline 7. A feeling that your hearing is muffled? & 1 & 2 & 3 & 4 & 5 & 6 & 7 \\
\hline
\end{tabular}

insertion depth of the catheter and to establish awareness of the proximity of the ICA. In this study, we evaluated the technical feasibility of this image-guided navigation balloon catheter system in patients with ETD.

\section{MATERIALS AND METHODS}

This study was approved by the Institutional Review Board of the Pusan National University Hospital (IRB No. H-1810-008071). All patients provided written informed consent before the study.

\section{Patients}

This study was performed at Pusan National University Hospital between January 2017 and August 2018. The inclusion criteria for BET were patients age $\geq 18$ years who could not do a Valsalva maneuver for more than 6 months and who suffered from persistent symptoms of: (1) unilateral or bilateral otitis media with effusion, (2) tympanic membrane retraction with type B or C tympanogram, or (3) were diagnosed with ETD. ETD was diagnosed when patients presented with 3 or more ET dysfunction symptoms (ear pain, ear pressure, tinnitus, cracking or popping in ears, muffled hearing, feeling that ears are clogged). All patients failed to improve despite medical therapy with topical steroids, anti-reflux medication and auto-inflation devices as minimum of 6 weeks. The exclusion criteria were: (1) history of

\section{H I G H L I I G H T S}

- An image-guided navigation balloon catheter provides surgeons with real-time feedback on the position of the catheter tip during balloon Eustachian tuboplasty.

- Clinical improvement-defined as the ability to perform a successful Valsalva maneuver-was found in $73.7 \%$ of ears at 6 months post-procedure.

- All patients had improved clinical symptoms (7-item Eustachian Tube Dysfunction Questionnaire) within 6 months, and showed no complications.

- Image-guided navigation balloon catheters are a potentially valuable tool, and are technically feasible in patients with Eustachian tube dilatory dysfunction. prior ET surgery, (2) ear tubes in place or an unhealed perforation, (3) follow-up duration less than 6 months. Clinical examinations were performed 1 week, 1 month, 3 months, and 6 months after the procedure. To describe symptoms, we used the 7-item Eustachian Tube Dysfunction Questionnaire (ETDQ-7) score [12] in Table 1 and subjective reporting of the ability to perform the Valsalva maneuver (yes or no).

\section{Preoperative computed tomography scan protocol}

Preoperative computed tomography (CT) was used for calibration and visualization of the cartilaginous portion of ET [13]. High-resolution paranasal CT scans were conducted using a GMS Revolution CT scanner (GE Healthcare, Milwaukee, WI, USA) with the patients in supine position, with and without Valsalva maneuver. The authors explained the Valsalva maneuver and procedure to all patients prior to their $\mathrm{CT}$ scan. The technician was instructed to ask the patients to exhale forcefully against a closed nose immediately before scanning. The axial plane imaging acquisition was performed at 1-mm thickness, $215 \mathrm{mAs}$, and $120 \mathrm{kVp}$. The CT scan was performed only once each with and without Valsalva maneuver due to radiation exposure. The mean total amount of radiation exposure (doselength product [DLP] and the volume CT dose index [CTDIvou]) were $583.6 \pm 15.2 \mathrm{mGy} \cdot \mathrm{cm}$ and $42.30 \pm 8.37 \mathrm{mGy}$.

\section{Balloon dilatation using the image-guided navigation balloon catheter}

Each patient underwent BET by using both the Naviloon (balloon and guide catheter) and the NET-Navigation (image guided navigation System; Medicore, Seongnam, Korea). The balloon catheter is designed to be inserted and inflated in the cartilaginous portion of the ET for treatment of ETD. The balloon catheter consists of a flexible proximal shaft, an actuator for advancing and retracting the balloon catheter, a rigid shaft that passes through the guide catheter, a balloon (length $16 \mathrm{~mm}$, diameter $6 \mathrm{~mm}$ at $12 \mathrm{~atm}$ ) at the distal end of the shaft for ET dilation, and a distal atraumatic tip that contains an electromagnetic navigation sensor (Fig. 1). The NET-Navigation target localization error for surface registration is less than $2 \mathrm{~mm}$. Although the balloon catheter was equipped with a navigation system, the catheter also has a black proximal endoscopic marker to aid in positioning under direct endoscopic visualization (Fig. 2). The 

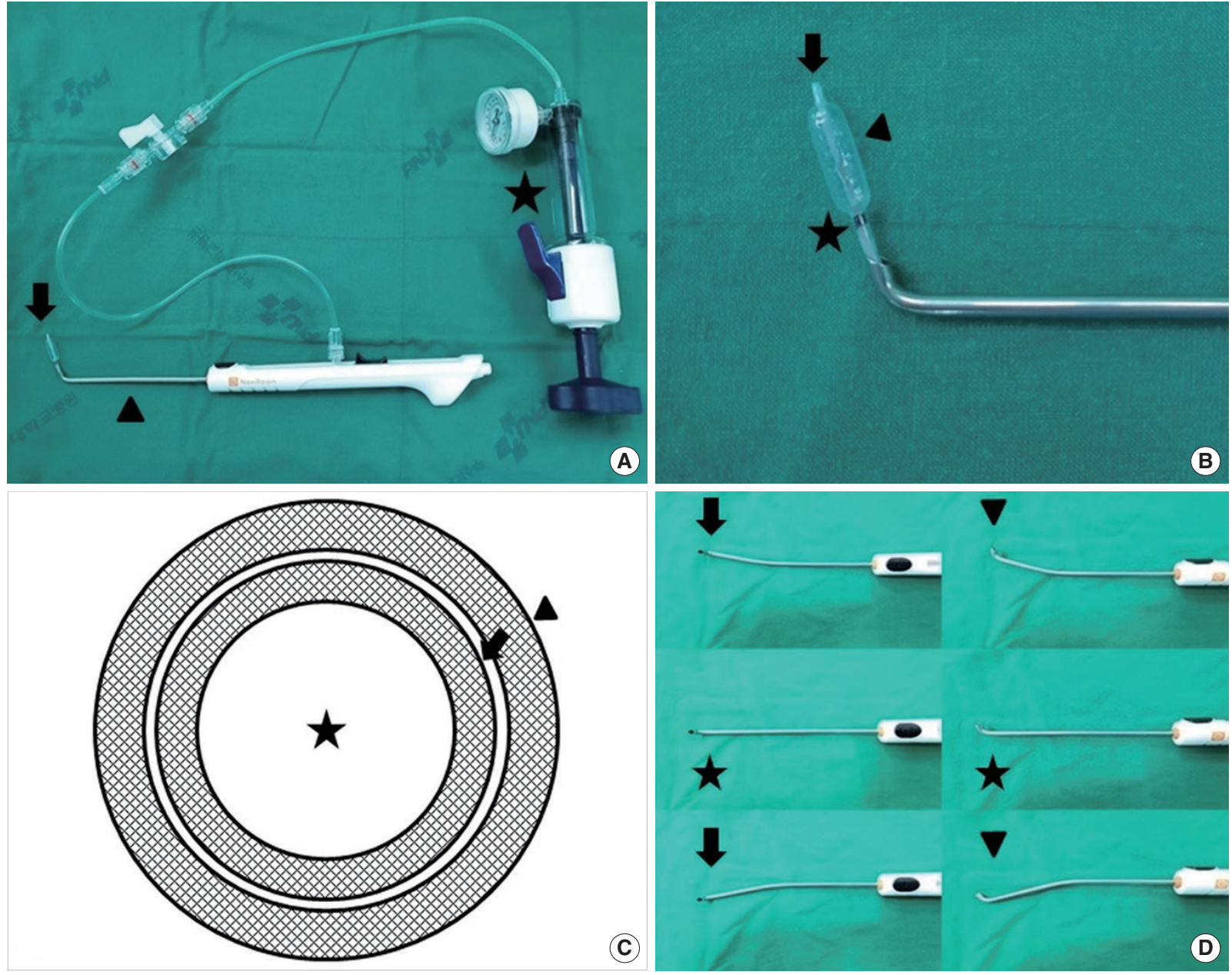

Fig. 1. (A) Photographs of the balloon catheter (arrow), guide catheter (arrowhead), and inflation device (asterisk). (B) Distal end of the balloon catheter, comprising an electromagnetic navigation sensor (arrow), a balloon (16 mm in length and $6 \mathrm{~mm}$ in diameter at 12 atm; arrowhead), and a black proximal balloon marker (asterisk). (C) Cross-sectional view of the balloon catheter consisting of an electromagnetic sensor part (0.9 $\mathrm{mm}$ in diameter; asterisk), inner tube (1.2 $\mathrm{mm}$ in diameter; arrow) and outer tube (1.6 mm in diameter; arrowhead). (D) Flexibility of the guide catheter. Neutral position (asterisks), right- and left-sided bending (arrows), and upward and downward bending (arrowheads).
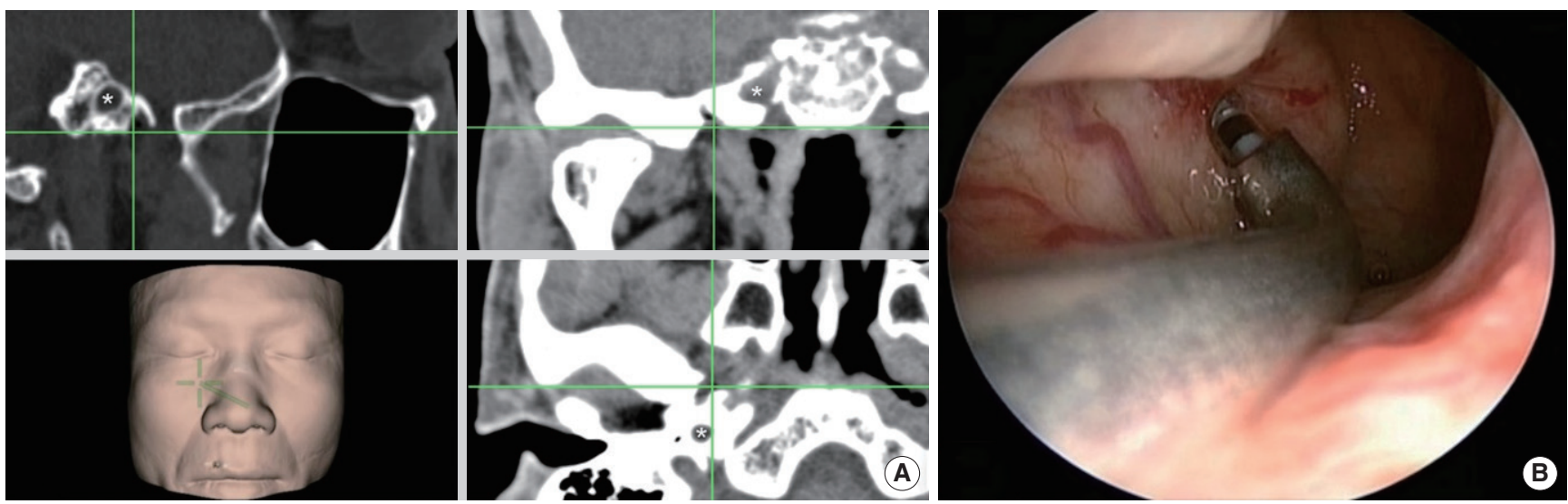

Fig. 2. (A) Intraoperative view showing the insertion depth of the catheter tip as confirmed during a balloon Eustachian tuboplasty procedure. The catheter tip was advanced until its tip reached the isthmus. The on-screen crosshair provided real-time localization in three dimensions. Intraoperative view showing the internal carotid artery (asterisks). (B) Endoscopic photograph of catheter tip insertion over a black proximal endoscopic marker (denoting canalization of the cartilaginous segment of the Eustachian tube). 
guide catheter is designed to provide a means to access the ET. Unlike other guide catheters, this device consists of a flexible shaft with a central lumen instead of a rigid shaft (Fig. 1). If anatomical variations such as deviated nasal septum, inferior turbinate hypertrophy, or narrow nasal cavity were present in the patient, surgeons can easily bend the flexible shaft according to the anatomical variation during BET. The catheter tip was used as a registration probe and contacted the face during the skin tracing process. All procedures were performed with endoscopic assistance $\left(30^{\circ}\right.$-view angle). A balloon was slowly passed through the ET lumen until it reached the isthmus with the cartilaginous portion of the ET, which was confirmed simultaneously by the navigation system. The balloon was inflated once with sterile water to a target pressure of up to $12 \mathrm{~atm}$ for 2 minutes, then deflated for 1 minute, and then reinflated for 1 more minute [14]. The details of a representative case are highlighted in Supplementary Video 1.

\section{RESULTS}

Patients' demographic characteristics are presented in Table 2. A retrospective review found that image-guided navigation-assisted BET had been performed in 38 ears ( 29 patients, nine bilat-

Table 2. Demographic and clinical characteristics of the treated patients

\begin{tabular}{|c|c|c|c|c|c|c|c|c|}
\hline \multirow{3}{*}{ Patient } & \multirow{3}{*}{$\begin{array}{l}\text { Sex/age } \\
(y r)\end{array}$} & \multirow{3}{*}{ Side } & \multirow{3}{*}{$\begin{array}{l}\text { Symptom } \\
\text { duration (yr) }\end{array}$} & \multirow{3}{*}{$\begin{array}{c}\text { Previous tympanostomy } \\
\text { tube history }\end{array}$} & \multirow{3}{*}{$\begin{array}{l}\text { Post-procedural } \\
\text { complication }\end{array}$} & \multicolumn{3}{|c|}{ Total ETDQ-7 score } \\
\hline & & & & & & \multirow{2}{*}{ Preoperative } & \multicolumn{2}{|c|}{ Post-procedure } \\
\hline & & & & & & & $1 \mathrm{mo}$ & $6 \mathrm{mo}$ \\
\hline 1 & $\mathrm{M} / 36$ & Right & 12 & Yes & No & 30 & 15 & 18 \\
\hline 2 & $\mathrm{M} / 39$ & Right & 14 & Yes & No & 32 & 31 & 15 \\
\hline 3 & $M / 32$ & Left & 9 & Yes & No & 27 & 22 & 26 \\
\hline \multirow[t]{2}{*}{4} & $M / 34$ & Right & 7 & Yes & No & 38 & 26 & 24 \\
\hline & & Left & 7 & Yes & No & 42 & 26 & 23 \\
\hline \multirow[t]{2}{*}{5} & $M / 38$ & Right & 8 & Yes & No & 19 & 14 & 9 \\
\hline & & Left & 8 & Yes & No & 35 & 23 & 10 \\
\hline \multirow[t]{2}{*}{6} & $F / 23$ & Right & 1 & No & No & 17 & 17 & 10 \\
\hline & & Left & 1 & No & No & 17 & 16 & 14 \\
\hline \multirow[t]{2}{*}{7} & $\mathrm{M} / 24$ & Right & 2 & Yes & No & 18 & 15 & 10 \\
\hline & & Left & 2 & Yes & No & 23 & 19 & 10 \\
\hline 8 & $\mathrm{M} / 18$ & Left & 3 & Yes & No & 36 & 15 & 32 \\
\hline 9 & $M / 23$ & Left & 1 & No & No & 20 & 22 & 10 \\
\hline \multirow[t]{2}{*}{10} & $M / 19$ & Right & 2 & No & Pain (otalgia) & 28 & 19 & 10 \\
\hline & & Left & 2 & No & Pain (otalgia) & 28 & 9 & 10 \\
\hline \multirow[t]{2}{*}{11} & $\mathrm{M} / 49$ & Right & 10 & Yes & No & 32 & 9 & 7 \\
\hline & & Left & 10 & Yes & No & 20 & 12 & 7 \\
\hline \multirow[t]{2}{*}{12} & $\mathrm{~F} / 43$ & Right & 20 & Yes & No & 17 & 9 & 7 \\
\hline & & Left & 20 & Yes & No & 30 & 21 & 19 \\
\hline 13 & $F / 31$ & Right & 16 & Yes & Blood-tinged nasal discharge & 26 & 17 & 11 \\
\hline 14 & $\mathrm{~F} / 55$ & Right & 17 & Yes & No & 18 & 16 & 7 \\
\hline 15 & $\mathrm{~F} / 53$ & Right & 12 & Yes & No & 29 & 15 & 17 \\
\hline 16 & $\mathrm{M} / 45$ & Left & 14 & Yes & No & 26 & 22 & 14 \\
\hline 17 & $\mathrm{~F} / 53$ & Right & 5 & Yes & No & 17 & 14 & 18 \\
\hline 18 & $M / 62$ & Left & 30 & Yes & No & 38 & 31 & 29 \\
\hline \multirow[t]{2}{*}{19} & $\mathrm{M} / 57$ & Right & 18 & Yes & No & 21 & 10 & 8 \\
\hline & & Left & 18 & Yes & No & 28 & 10 & 11 \\
\hline \multirow[t]{2}{*}{20} & $\mathrm{M} / 42$ & Right & 3 & No & No & 17 & 13 & 13 \\
\hline & & Left & 3 & No & No & 15 & 12 & 18 \\
\hline 21 & $F / 21$ & Left & 7 & Yes & Blood-tinged nasal discharge & 17 & 19 & 7 \\
\hline 22 & $\mathrm{~F} / 58$ & Right & 10 & Yes & No & 19 & 9 & 7 \\
\hline 23 & $\mathrm{M} / 47$ & Right & 10 & Yes & No & 27 & 19 & 17 \\
\hline 24 & $F / 29$ & Right & 5 & No & No & 24 & 23 & 26 \\
\hline 25 & $\mathrm{M} / 39$ & Right & 10 & Yes & No & 30 & 21 & 17 \\
\hline 26 & $\mathrm{M} / 54$ & Right & 15 & Yes & No & 26 & 15 & 15 \\
\hline 27 & $\mathrm{M} / 44$ & Right & 7 & No & No & 28 & 26 & 22 \\
\hline 28 & $\mathrm{M} / 45$ & Left & 13 & Yes & No & 19 & 9 & 10 \\
\hline 29 & $\mathrm{M} / 54$ & Left & 4 & No & No & 34 & 26 & 13 \\
\hline
\end{tabular}

ETDQ-7, 7-item Eustachian Tube Dysfunction Questionnaire. 
eral, 21 right ears and 17 left ears). Twenty of the patients were men and 9 were women, with an age range of 18 to 62 years (mean, 38.6 \pm 13.1 years). Sixteen ears had otitis media with effusion with type B tympanograms, and 22 ears had retracted tympanic membranes with type $\mathrm{B}$ or $\mathrm{C}$ tympanograms. To evaluate the effectiveness of the surgical procedure, we analyzed patients' clinical records from the final visit at 6 months post-procedure. The mean total ETDQ-7 score was $25.4 \pm 7.1$ preoperatively, $17.5 \pm 6.2$ at 1 month, and $15.2 \pm 7.0$ at 6 months. Statistically significant differences were found between the preoperative ETDQ-7 score and both the 1-month and 6-month followup scores $(P<0.001$, paired $t$-test $)$ (Fig. 3$)$. It was possible to perform a successful Valsalva maneuver in 28 of the 38 ears $(73.7 \%)$ at the final visit. In a comparison of preoperative and postoperative CT scans taken during the Valsalva maneuver, ET patency was visually confirmed at 6 months after the operation (Fig. 4). Otomicroscopy demonstrated that 10 of the 16 ears $(62.5 \%)$ with type B tympanograms appeared normal, with type A tympanograms at the time of the patients' final visit. Additionally, 15 of the $22(68.2 \%)$ ears with retracted tympanic membrane appeared normal; although the remaining 7 (31.2\%) of these cases still had retraction, they showed a significant improvement of the total ETDQ-7 score compared with the preoperative score. There were no major complications related to balloon dilation.

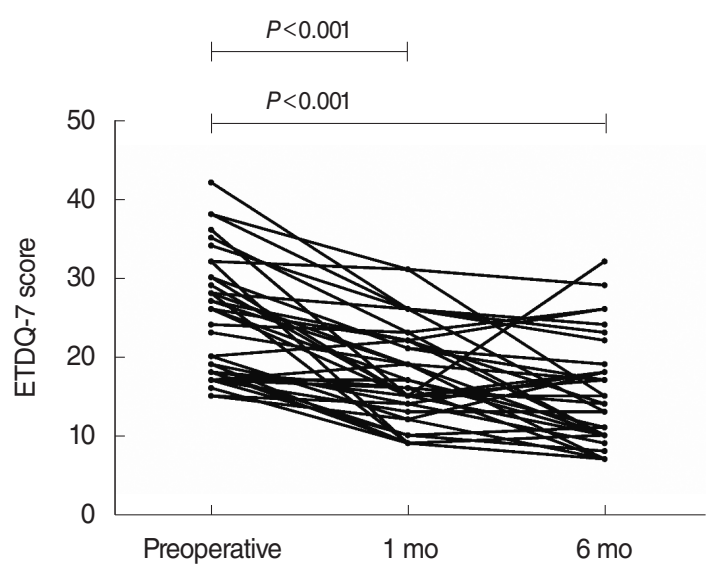

Fig. 3. Total 7-item Eustachian Tube Dysfunction Questionnaire (ETDQ-7) scores preoperatively, and at 1 month and 6 months postprocedure.
Two patients (two ears) had blood-tinged nasal discharge and two ears (one patient) had otalgia, which disappeared spontaneously within a day. BET was safely performed in all patients and was evaluated as technically successful. In all patients, we were able to confirm the insertion depth of the catheter and to establish awareness of the proximity of the ICA during the BET procedure (Fig. 2).

\section{DISCUSSION}

BET has emerged as a new minimally invasive intervention used for the treatment of ETD $[15,16]$. In this study, we developed an image-guided navigation balloon catheter to be used during BET to treat ETD. We hypothesized that image-guided navigation balloon catheter insertion may be a complementary method to the standard technique, because the balloon catheter tip can be identified during the procedure. It is critical to confirm the position of the catheter tip during BET, as a potential risk of the BET procedure is that a false passage may be created by the balloon catheter, especially when introducing the catheter tip [8,17-19]. Although cadaveric studies have documented intentional dilation of the bone on postprocedural CT scans, this does not rule out the possibility of a micro-fracture along a bony canal $[4,8]$.To avoid catastrophic injury, it is clinically important to recognize the proximity of the ICA.

Previous researchers have reported a variety of clinical success rates for BET. According to the recent study of Poe et al. [20], the Valsalva maneuver showed improvement at all follow-up times, but there was a decline from $100 \%$ positive Valsalva maneuvers after balloon dilation to $63 \%$ after a period of 7 to 14 months. Schroder et al. [21] reported a 1-year improvement rate of $73 \%$ in 1,076 ETs in 622 patients; $82 \%$ of the patients with initial improvement maintained their improvement for 5 years. In a study of 42 ETs, Silvola et al. [22] reported an $80 \%$ improvement rate that remained stable for 2 years. This study showed similar results, with an improvement rate of $73.7 \%$. Moreover, all patients had improved clinical symptoms (ETDQ-7 scores) at the 6-month follow-up.

In this study, there were no procedure-related complications. BET was safely performed in all patients and considered techni-
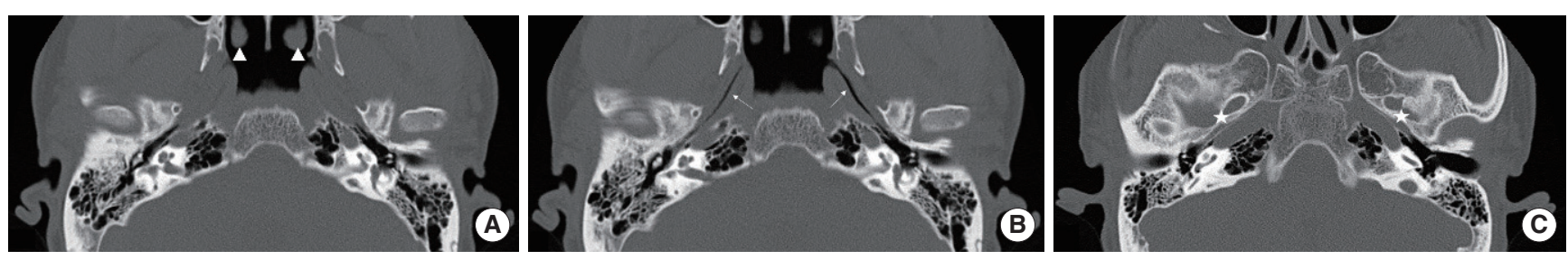

Fig. 4. (A) Preoperative computed tomography (CT) scans during the Valsalva maneuver, showing the nasopharyngeal end of the Eustachian tube (arrowheads). (B) Six-month postoperative CT scans during the Valsalva maneuver, showing patency of the cartilaginous Eustachian tube (arrows). (C) Six-month postoperative CT scans without the Valsalva maneuver. No micro-fracture was found along the bony canal of the internal carotid artery (asterisks). 
cally successful. During all of the BET procedures, we were able to confirm the insertion depth of the catheter and establish awareness of the proximity of the ICA. There is no risk of injury during insertion posed by the surrounding surgical structures because the catheter has a distal atraumatic tip that contains an electromagnetic navigation sensor. This device was deemed technically feasible. The use of an image-guided navigation balloon catheter during BET is simple and convenient, and no additional training was required for otology surgeons who had experience with conventional BET. Additionally, except for a calibration time of roughly 10 minutes, no additional operation time is required.

Previous studies have reported that continuous visualization of the balloon catheter may be possible using a dual endoscopic transtympanic approach $[13,23,24]$. However, this technique has not been widely adopted because of its complexity, and it also does not provide full visualization of the balloon catheter and ET. Our results suggest that continuous visualization of the balloon catheter using the image-guided navigation balloon catheter decreases the risk of contortion, allows the surgeon to confirm the correct position of the catheter tip, and reduces the chance of insertion into a false passage, such as the carotid canal.

Compared to conventional BET without navigation, radiation exposure may be a concern because of the requirement for a preoperative CT scan; however, as measurements of the mean total amount of radiation exposure, the DLP and the CTDIVoL were 583.6 $\pm 15.2 \mathrm{mGy} \cdot \mathrm{cm}$ and $42.30 \pm 8.37 \mathrm{mGy}$, respectively, which convert to an effective dose of less than $2 \mathrm{mSv}[25,26]$. The effective dose from the CT scan is broadly comparable to that of natural background radiation (cosmic, terrestrial, and internal), which accounts for $1 \mathrm{mSv}$ per year, and the average radon exposure in the United States, which is $2 \mathrm{mSv}$ per year [25].

Although our preliminary study demonstrated several advantages of using image-guided navigation during BET, it has some limitations. First, the number of cases identified was small, since ETD is an uncommon disease. Second, for similar reasons, this study had no external control group and was a single-center study. Third, there is still no consensus on post-procedure evaluation methods. However, the ETDQ-7 assesses symptoms of ET dysfunction and is the only patient-reported outcomes tool to have undergone an initial validation study [27]. For these reasons, further multi-center studies with larger sample sizes are required to validate our results.

Our preliminary findings indicate that image-guided navigation balloon catheter insertion allowed us to clearly monitor the location of the catheter tip during BET. This provides the surgeon with real-time feedback on the position of the catheter tip during BET and prevents the creation of a false passage using the balloon catheter. It is a potentially valuable tool in patients with ETD, and it is technically feasible. The application of an image-guided navigation balloon catheter during BET is simple, convenient, and effective. In conclusion, although further studies are needed, the results of image-guided navigation balloon cath- eter insertion were encouraging.

\section{CONFLICT OF INTEREST}

No potential conflict of interest relevant to this article was reported.

\section{ORCID}

Sung-Won Choi https://orcid.org/0000-0002-7463-7720

Seok-Hwan Lee https://orcid.org/0000-0002-5044-6735

Se-Joon Oh https://orcid.org/0000-0001-8910-0064

Soo-Keun Kong https://orcid.org/0000-0002-6783-3766

\section{AUTHOR CONTRIBUTIONS}

Conceptualization: SKK. Data curation: SWC. Formal analysis: SHL, Methodology: SJO: Visualization: SWC. Writing-original draft: SWC.Writing-review \& editing: SKK.

\section{SUPPLEMENTARY MATERIALS}

Supplementary materials can be available at https://doi.org/10. 21053/ceo.2019.01305.

\section{REFERENCES}

1. Martino E, DiThaden R, Krombach GA, Westhofen M. Function tests for the Eustachian tube: current knowledge. HNO. 2004 Nov;52(11): 1029-39.

2. Browning GG, Gatehouse S. The prevalence of middle ear disease in the adult British population. Clin Otolaryngol Allied Sci. 1992 Aug; 17(4):317-21.

3. Luukkainen V, Kivekas I, Hammaren-Malmi S, Rautiainen M, Poyhonen L, Aarnisalo AA, et al. Balloon Eustachian tuboplasty under local anesthesia: is it feasible? Laryngoscope. 2017 May;127(5): 1021-5.

4. Ockermann T, Reineke U, Upile T, Ebmeyer J, Sudhoff HH. Balloon dilation eustachian tuboplasty: a feasibility study. Otol Neurotol. 2010 Sep;31(7):1100-3.

5. Catalano PJ, Jonnalagadda S, Yu VM. Balloon catheter dilatation of Eustachian tube: a preliminary study. Otol Neurotol. 2012 Dec;33(9): 1549-52.

6. Miller BJ, Elhassan HA. Balloon dilatation of the Eustachian tube: an evidence-based review of case series for those considering its use. Clin Otolaryngol. 2013 Dec;38(6):525-32.

7. Randrup TS, Ovesen T. Balloon eustachian tuboplasty: a systematic review. Otolaryngol Head Neck Surg. 2015 Mar;152(3):383-92.

8. Poe DS, Hanna BM. Balloon dilation of the cartilaginous portion of the eustachian tube: initial safety and feasibility analysis in a cadaver model.Am J Otolaryngol. 2011 Mar-Apr;32(2):115-23. 
9. Ashry Y, Kawai K, Poe D. Utility of adjunctive procedures with balloon dilation of the Eustachian tube. Laryngoscope Investig Otolaryngol. 2017 Nov;2(6):337-43.

10. Kepchar J, Acevedo J, Schroeder J, Littlefield P. Transtympanic balloon dilatation of eustachian tube: a human cadaver pilot study. J Laryngol Otol. 2012 Nov;126(11):1102-7.

11. Busby DR, Slemmons DH, Miller TF Jr. Fatal epistaxis via carotid aneurysm and eustachian tube. Arch Otolaryngol. 1968 Mar;87(3): 295-8.

12. McCoul ED,AnandVK, Christos PJ.Validating the clinical assessment of eustachian tube dysfunction: The Eustachian Tube Dysfunction Questionnaire (ETDQ-7). Laryngoscope. 2012 May;122(5):1137-41.

13. Tarabichi M, Najmi M.Visualization of the eustachian tube lumen with Valsalva computed tomography. Laryngoscope. 2015 Mar;125(3): 724-9.

14. Poe DS, Silvola J, Pyykko I. Balloon dilation of the cartilaginous eustachian tube. Otolaryngol Head Neck Surg. 2011 Apr;144(4):563-9.

15. Hwang SY, Kok S, Walton J. Balloon dilation for eustachian tube dysfunction: systematic review. J Laryngol Otol. 2016 Jul;130 Suppl 4: S2-6.

16. Williams B, Taylor BA, Clifton N, Bance M. Balloon dilation of the Eustachian tube: a tympanometric outcomes analysis. J Otolaryngol Head Neck Surg. 2016 Feb;45:13.

17. Ockermann T, Reineke U, Upile T, Ebmeyer J, Sudhoff HH. Balloon dilatation eustachian tuboplasty: a clinical study. Laryngoscope. 2010 Jul;120(7):1411-6.

18. Bowles PF,Agrawal S, Salam MA. Balloon tuboplasty in patients with Eustachian tube dysfunction: a prospective study in 39 patients (55 ears). Clin Otolaryngol. 2017 Oct;42(5):1057-60.
19. Jufas N,Treble A, Newey A, Patel N. Endoscopically guided transtympanic balloon catheter dilatation of the eustachian tube: a cadaveric pilot study. Otol Neurotol. 2016 Apr;37(4):350-5.

20. Poe D, AnandV, Dean M, Roberts WH, Stolovitzky JP, Hoffmann K, et al. Balloon dilation of the eustachian tube for dilatory dysfunction: a randomized controlled trial. Laryngoscope. 2018 May;128(5): 1200-6.

21. Schroder S, Lehmann M, Ebmeyer J, Upile T, Sudhoff H. Balloon Eustachian tuboplasty: a retrospective cohort study. Clin Otolaryngol. 2015 Dec;40(6):629-38.

22. Silvola J, Kivekas I, Poe DS. Balloon dilation of the cartilaginous portion of the Eustachian tube. Otolaryngol Head Neck Surg. 2014 Jul; 151(1):125-30.

23. Jufas N, Patel N. Transtympanic balloon dilatation of the eustachian tube: systematic review. J Laryngol Otol. 2016 May;130(5):425-30.

24. McCoul ED, AnandVK. Eustachian tube balloon dilation surgery. Int Forum Allergy Rhinol. 2012 May-Jun;2(3):191-8.

25. HudaW, Ogden KM, Khorasani MR. Converting dose-length product to effective dose at CT. Radiology. 2008 Sep;248(3):995-1003.

26. Christner JA, Kofler JM, McCollough CH. Estimating effective dose for CT using dose-length product compared with using organ doses: consequences of adopting International Commission on Radiological Protection publication 103 or dual-energy scanning. AJR Am J Roentgenol. 2010 Apr;194(4):881-9.

27. Schilder AG, Bhutta MF, Butler CC, Holy C, Levine LH, Kvaerner $\mathrm{KJ}$, et al. Eustachian tube dysfunction: consensus statement on definition, types, clinical presentation and diagnosis. Clin Otolaryngol. 2015 Oct;40(5):407-11. 